\title{
Technology and Sustainability in the Framework of Corporate Social Responsibility
}

\author{
Marta Peris-Ortiz ${ }^{1, *}$ and Antonio Luis Leal-Rodríguez ${ }^{2}$ (i) \\ 1 Business Organisation Department, Universitat Politècnica de València, 46022 Valencia, Spain \\ 2 Business Administration and Marketing Department, Universidad de Sevilla, 41018 Sevilla, Spain; \\ lealrodriguez@us.es \\ * Correspondence: mperis@doe.upv.es
}

Received: 10 October 2020; Accepted: 11 October 2020; Published: 13 October 2020

Each one of the three concepts that comprise the title of this Special Issue has a relevant weight in their own sector, as well as in management literature in general. Likewise, when these concepts are associated with each other and/or complement other social or economic concepts, they give rise to major problem areas to be investigated. Below, we make a brief reference to two of these concepts, highlighting several of the reasons for their importance. Subsequently, we shall examine the logic which joins them, in which, in a different way, each of the articles published herein are situated.

In reference to Corporate Social Responsibility (CSR), which serves as the framework and link to the other two concepts, its importance has not ceased to grow since the 1960s [1-3]. The sustained economic growth starting from that decade in most developed countries, except for its slowdown or fall during the oil crisis and the major subprime mortgage crisis, has modified the material, technological, and social conditions, fueling the possibility of several distinct forms of competition in which it is more compatible to achieve the benefit, and simultaneously, the social good [4-7]. For this issue, it is possible to add the new awareness of consumers in relation to the necessary ecological preservation of the environment [8], and the national and international standards and regulations which arise to protect natural resources [9-11]. In this sense, society's awareness about essential sustainability changes the relation of companies with their markets in a different cultural framework.

In this way, with their increasingly greater influence, CSR and sustainability comprise the framework which is described in the article by Boronat-Navarro, M, y Pérez-Aranda, J. A.: "Analyzing willingness to pay more to stay in a sustainable hotel". By means of a suitable sampling technique on an extensive population of 7,874,941 tourists who had an overnight stay of at least one night in the city of Barcelona in 2014, this article contrasts the hypothesis to be verified: (1) If the consumers who seek information about the CSR practices in the hotels want to make use of these hotels even though this entails a higher price; (2) if the people who are interested in knowing the certifications about the sustainability practices of these hotels want to use them even though this means assuming a higher price; and (3) if the consumers with prior experience in hotels with sustainability policies and practices are willing to assume a higher price.

As we have mentioned above, the mere approach of this study illustrates society's orientation, or at least one significant part of it, towards products and services which preserve sustainability. On the other hand, as the authors explain, the results of this research have evident value for discovering consumer behaviors in this sector and facilitates the management of these businesses.

In the same line as the previous article in reference to CSR, but situating the aim of this study in the organization, Hu, B., Zhang, T., and Yan S. proposed the article: "How corporate social responsibility influences business model innovation: the mediating role of organizational legitimacy". Both the empirical work and the conceptual construction of the article show that, effectively, the company policies in favor of CSR have a positive influence on the innovation of the business models (BM) and 
in the organization's legitimacy or the perception of legitimacy which the members of the company have when seeing that it fulfills its mission and uses the suitable means for this, in accordance with the facts and ideas. "BM innovation, as the authors state, needs the firm to reduce employee resistance and improve employee commitment and participation, because employees determine the efficiency of resource allocation and use in BM innovation. Internal legitimacy can enhance employee dedication, satisfaction, and cohesion due to the fact that it improves employee trust and recognition, which in turn can lead to greater efficiency of resource allocation and use."

On the other hand, in continuation with the organization as a subject of study, Acosta-Prado, J. C., López-Montoya, O. H., Sanchís-Pedregosa, C., and Vázquez-Martínez, U. J. present the article: "Sustainable orientation of management capability and innovative performance: the mediating effect of knowledge management", which is based on the theories of knowledge and learning, Resource Based View (RBV) and Dynamic Capability View (DCV), and it particularly deals with the empirical research about 331 Health Provider Institutions (HPIs) in Colombia.

In the companies from the health care sector that were researched, the article describes their CSR policies with the main purpose of sustainability, with the innovative performance of these companies and their effective achievement of sustainability through two sequences: (1) a sequence which links the management capabilities with the innovative performance in a direct way; and (2) the sequence which relates the management capabilities and innovative performance through the intermediation of knowledge management. These two sequences give rise to a model which sis the subject of the empirical research, and one plausible interpretation is that the capabilities in the first case, with their tacit knowledge component [12], encompass and influence the innovative performance of the companies. While in the second case, in which the knowledge management intermediates the relation of the bundle of capabilities-innovative performance, the explicit knowledge and the management's will shall guide the innovation in a more deliberate way [13], hence facilitating the sustainability proposal.

The article to which we refer below: "A conceptual framework to manage resilience and increase sustainability in the supply chain" by Zavala-Alcívar, A., Verdecho, M-J. and Alfaro-Saiz, J-J., carries out a broad review of the literature about the supply chains, with the aim to establish a conceptual model which makes resilience and sustainability compatible and provokes desirable synergies between them. The supply chains must face the challenge of more complex forms of collaboration in the global economy, in which unexpected events will occur which require a response capability to maintain the performance level and, at the same time, the sustainability in its three dimensions: economic, social, and environmental.

In this way, the supply chains, like other organizational systems or business models that must be managed, must follow a series of principles and rely on a series of elements in order to improve or preserve their operation in the markets. For this purpose, based on the proposal made by the authors, Ali et al. (2017) [14] and Cristopher and Peck (2004) [15], one of the paths that appear as relevant to achieve resilience and the sustainability consists of: (1) manage by following the principles of redundancy and flexibility of the reengineering, (2) carry out the collaboration based on trust, shared information, versatility (visibility and speed), and a management culture of the supply chain which, based on leadership and the innovation capability, face the risk of unexpected events.

What the authors propose in the article is how to manage the complex system of supply chains so that they are resilient and provide sustainability, correspond to the management of complex systems where flexibility, knowledge management, awareness of the disruptive environment, and the design of contingency plans are essential elements for success. These are the results from the systematic study of the literature about the supply chains in the global economy.

Finally, with further emphasis on the supply chains, Rius-Sorolla, G., Estelles-Miguel, S., and Rueda-Armengot, C. contributed the article: "Multivariable supplier segmentation in sustainable supply chain management" as the final collaboration to this special issue. This article describes several of the technical and methodological aspects which make it possible to segment the supply chain, using this segmentation to select and improve each phase of the chain, seeking the best options step 
by step. Accordingly, in addition to achieving resilience against the risk of unexpected events, it also seeks sustainability. Greater efficiency and greater resilience and, at the same time, additional CSR above all, focused on sustainability, simultaneously complying with society and the markets, with the commitment that is demanded by stakeholders, and with the obligations with the stockholders.

In the authors' own words, "this article presents the steps that should be followed in supply chain management, the identification of risks, and the new leadership of purchasing management to develop a sustainable supply chain. To this end, some of the key industrial actions reported in the literature are outlined, and two case studies are presented to identify the steps for the segmentation and dynamic development of suppliers".

Funding: This research received no external funding.

Conflicts of Interest: The authors declare no conflict of interest.

\section{References}

1. Burke, I.; Logsdon, J.M. How Corporate Social Responsibility pays off. Long Range Plan. 1996, 29, 495-502.

2. Carroll, A.B. Business and Society: Ethics and Stakeholder Management; South-Western Publishing Company: Cincinnati, OH, USA, 1989.

3. Carroll, A.B. Corporate Social Responsibility: Evolution of a definitional construct. Bus. Soc. 1999, 38, 268-295. [CrossRef]

4. Crane, A.; Palazzo, G.; Spence, L.J.; Matten, D. Contesting the value of "creating shared value". Calif. Manag. Rev. 2014, 56, 130-155. [CrossRef]

5. Porter, M.E.; Kramer, M.R. Strategy and society: The link between Competitive Advantage and Corporate Social Responsibility. Harv. Bus. Rev. 2006, 84, 78-92. [PubMed]

6. Porter, M.E.; Kramer, M.R. Creating Shared Value. Harv. Bus. Rev. 2011, 89, 62-77.

7. Gartenberg, C.; Serafeim, G. 181 Top CEOs Have Realized Companies Need a Purpose Beyond Profit. Available online: http://hbr.org (accessed on 1 October 2020).

8. Chen, Y.-S.; Lai, S.-B.; Wen, C.-T. The influence of green innovation performance on corporate advantage in Taiwan. J. Bus. Ethics 2006, 67, 331-339. [CrossRef]

9. Chen, Y.-S. The driver of green innovation and green image-green core competence. J. Bus. Ethics 2008, 81, 531-543. [CrossRef]

10. Kolk, A. The social responsibility of international business: From ethics and the environment to CSR and sustainable development. J. World Bus. 2016, 51, 23-34. [CrossRef]

11. Leal-Rodriguez, A.L.; Ariza-Montes, A.J.; Morales-Fernandez, E.; Albort-Morant, G. Green innovation, indeed a cornerstone in linking market requests and business performance. Evidence from the Spanish automotive components industry. Technol. Forecast. Soc. Chang. 2018, 129, 185-193. [CrossRef]

12. Nonaka, I.; Takeuchi, H. The Knowledge Creating Company: How Japanese Companies Create the Dynamics of Innovation; Oxford Economic Press: New York, NY, USA, 1995.

13. Santos, F.M.; Eisenhardt, K.M. Organizational boundaries and theories of organization. Organ. Sci. 2005, 16, 491-508. [CrossRef]

14. Ali, A.; Mahfouz, A.; Arisha, A. Analysing supply chain resilience: Integrating the constructs in a concept mapping framework via a systematic literature review. Supply Chain Manag. Int. J. 2017, 22, 16-39. [CrossRef]

15. Cristopher, M.; Peck, H. Building the resilient supply chain. Int. J. Logist. Manag. 2004, 15, 1-14. [CrossRef]

(C) 2020 by the authors. Licensee MDPI, Basel, Switzerland. This article is an open access article distributed under the terms and conditions of the Creative Commons Attribution (CC BY) license (http://creativecommons.org/licenses/by/4.0/). 